\title{
Selection of appropriate end-points (pCR vs 2yDFS) for tailoring treatments with prediction models in locally advanced rectal cancer
}

Citation for published version (APA):

Valentini, V., van Stiphout, R. G. P. M., Lammering, G., Gambacorta, M. A., Barba, M. C., Bebenek, M., Bonnetain, F., Bosset, J. F., Bujko, K., Cionini, L., Gerard, J. P., Roedel, C., Sainato, A., Sauer, R., Minsky, B. D., Collette, L., \& Lambin, P. (2015). Selection of appropriate end-points (pCR vs 2yDFS) for tailoring treatments with prediction models in locally advanced rectal cancer. Radiotherapy and Oncology, 114(3), 302-309. https://doi.org/10.1016/j.radonc.2015.02.001

Document status and date:

Published: 01/03/2015

DOI:

10.1016/j.radonc.2015.02.001

Document Version:

Publisher's PDF, also known as Version of record

Document license:

Taverne

Please check the document version of this publication:

- A submitted manuscript is the version of the article upon submission and before peer-review. There can be important differences between the submitted version and the official published version of record.

People interested in the research are advised to contact the author for the final version of the publication, or visit the DOI to the publisher's website.

- The final author version and the galley proof are versions of the publication after peer review.

- The final published version features the final layout of the paper including the volume, issue and page numbers.

Link to publication

\footnotetext{
General rights rights.

- You may freely distribute the URL identifying the publication in the public portal. please follow below link for the End User Agreement:

www.umlib.nl/taverne-license

Take down policy

If you believe that this document breaches copyright please contact us at:

repository@maastrichtuniversity.nl

providing details and we will investigate your claim.
}

Copyright and moral rights for the publications made accessible in the public portal are retained by the authors and/or other copyright owners and it is a condition of accessing publications that users recognise and abide by the legal requirements associated with these

- Users may download and print one copy of any publication from the public portal for the purpose of private study or research.

- You may not further distribute the material or use it for any profit-making activity or commercial gain

If the publication is distributed under the terms of Article $25 \mathrm{fa}$ of the Dutch Copyright Act, indicated by the "Taverne" license above, 
End-points in rectal cancer

\title{
Selection of appropriate end-points (pCR vs 2yDFS) for tailoring treatments with prediction models in locally advanced rectal cancer
}

\author{
Vincenzo Valentini $^{\mathrm{a}, 1}$, Ruud G.P.M. van Stiphout ${ }^{\mathrm{b}, \mathrm{c}, 1, *}$, Guido Lammering ${ }^{\mathrm{b}}$, Maria A. Gambacorta ${ }^{\mathrm{d}}$, \\ Maria C. Barba ${ }^{\mathrm{d}}$, Marek Bebenek ${ }^{\mathrm{e}}$, Franck Bonnetain ${ }^{\mathrm{f}}$, Jean F. Bosset ${ }^{\mathrm{g}}$, Krzysztof Bujko ${ }^{\mathrm{h}}$, Luca Cionini ${ }^{\mathrm{i}}$, \\ Jean P. Gerard ${ }^{\mathrm{j}}$, Claus Rödel ${ }^{\mathrm{k}}$, Aldo Sainato ${ }^{\mathrm{i}}$, Rolf Sauer ${ }^{1}$, Bruce D. Minsky ${ }^{\mathrm{m}}$, Laurence Collette $^{\mathrm{n}}$, \\ Philippe Lambin ${ }^{\mathrm{b}}$
}

\begin{abstract}
${ }^{a}$ Department of Radiotherapy, Università Cattolica S. Cuore, Rome, Italy; ${ }^{\mathrm{b}}$ Department of Radiation Oncology (MAASTRO), University Medical Centre Maastricht; ${ }^{\mathrm{c}}$ Department of Knowledge Engineering, Maastricht University, The Netherlands; ${ }^{\mathrm{d}}$ Bioimmagini e Scienze Radiologiche, Università Cattolica S. Cuore, Rome, Italy; ${ }^{\mathrm{e}}$ Department of Surgical Oncology, Silesian Oncological Centre, Wroclaw, Poland; ${ }^{\mathrm{f}}$ Department of Statistics, Faculté Médecine Dijon; ${ }^{\mathrm{g}}$ Department of Radiotherapy, CHU Besançon, France; ${ }^{\mathrm{h}}$ Department of Radiotherapy, The Maria Sklodowska-Curie Memorial Cancer Centre, Warsaw, Poland; ${ }^{\mathrm{i}}$ Department of Radiotherapy, Azienda Ospedaliera Universitaria Pisana, Pisa, Italy; ${ }^{\mathrm{j}}$ Department of Radiotherapy, Centre Antoine Lacassagne, Nice, France; ${ }^{\mathrm{k}}$ Department of Radiotherapy and Oncology, University of Frankfurt; ${ }^{1}$ Department of Radiotherapy, University of Erlangen, Germany; ${ }^{\mathrm{m}}$ Department of Radiation Oncology, University of Texas MD Anderson Cancer Center Houston, USA; ${ }^{\mathrm{n}}$ Department of Statistics, EORTC Headquarters, Brussels, Belgium
\end{abstract}

\section{A R T I C L E I N F O}

\section{Article history:}

Received 13 June 2013

Received in revised form 1 February 2015

Accepted 3 February 2015

Available online 21 February 2015

\section{Keywords:}

Rectal cancer

Pathological complete response

Disease-free survival

Risk ratio

Personalized treatment

Prediction models

\begin{abstract}
A B S T R A C T
Purpose: Personalized treatments based on predictions for patient outcome require early characterization of a rectal cancer patient's sensitivity to treatment. This study has two aims: (1) identify the main patterns of recurrence and response to the treatments (2) evaluate pathologic complete response (pCR) and two-year disease-free survival (2yDFS) for overall survival (OS) and their potential to be relevant intermediate endpoints to predict.

Methods: Pooled and treatment subgroup analyses were performed on five large European rectal cancer trials (2795 patients), who all received long-course radiotherapy with or without concomitant and/or adjuvant chemotherapy. The ratio of distant metastasis (DM) and local recurrence (LR) rates was used to identify patient characteristics that increase the risk of recurrences.

Findings: The DM/LR ratio decreased to a plateau in the first 2 years, revealing it to be a critical follow-up period. According to the patterns of recurrences, three patient groups were identified: $5-15 \%$ had pCR and were disease free after 2 years (excellent prognosis), 65-75\% had no pCR but were disease free (good prognosis) and $15-30 \%$ had neither pCR nor 2yDFS (poor prognosis).

Interpretation: Compared with pCR, 2yDFS is a stronger predictor of OS. To adapt treatment most efficiently, accurate prediction models should be developed for $\mathrm{pCR}$ to select patients for organ preservation and for $2 \mathrm{yDFS}$ to select patients for more intensified treatment strategies.
\end{abstract}

(c) 2015 Elsevier Ireland Ltd. All rights reserved. Radiotherapy and Oncology 114 (2015) 302-309
To improve cancer treatment, new hypotheses need to be tested faster in a suitable cohort of patients to avoid diluting treatment for insensible patients. Common methods include the use of large databases [1] and development of reliable surrogate endpoints. A typical example of such an endpoint is the finding that two-year disease-free survival (DFS) is correlated with six-year overall survival (OS) for stage III colon cancer patients treated with adjuvant chemotherapy [2]. Such surrogate endpoints can be identified early and have a high prognostic value for survival. By treating them not as prognostic factors but as intermediate outcomes that can be

\footnotetext{
* Corresponding author at: MAASTRO Clinic, Dr Tanslaan 12, PO Box 1588, 6201 BN Maastricht, The Netherlands.

E-mail address: ruud.vanstiphout@maastro.nl (R.G.P.M. van Stiphout).

${ }^{1}$ Equal contribution to this work.
}

predicted by statistical models, future clinical trials could evaluate individualized treatment strategies, with treatment randomization differentiated according to these predictions. An example of this strategy is model based decision making using imaging based tumor response predictions, which has potential for radiotherapy boost decisions [3].

Patients with rectal cancer exhibit heterogeneous responses to treatment; Studies identified a subpopulation of patients whose tumor is technically unresectable or who refused surgery but were cured with a low dose of radiotherapy [4]. This subpopulation is characterized by slow growth and long regression time of rectal cancer. Patients who achieved a pCR are considered to be a more favorable subpopulation with less LR and DM as well as better OS $[5,6]$. While the prediction of early intermediate endpoints (e.g., pCR) is less prone to uncertainties and may therefore be more 
accurate for individualizing treatment, these endpoints may be weaker prognosticators of long-term outcome.

In this study the value of both DFS and pCR is reported as intermediate endpoints for overall survival in locally advanced rectal cancer patients. The first aim of this study is to identify the optimal time point to assess DFS to best separate the population for their recurrence patterns. A combination of treatment heterogeneity and a large number of patients in the pooled trial dataset allowed for sub group analyses of recurrence and response patterns. Inspired by Gelman et al. [7] patterns of recurrence are analyzed by calculating the ratio of DM rate and LR rate (which are handled in general as competing risks) over time to identify a subset of patients with more versus less aggressive disease.

The second aim of the study was to evaluate pathologic complete response (pCR) and two-year disease-free survival (2yDFS) as intermediate endpoints in order to build predictive models which are able to identify patient subgroups before and during treatment. The rate of pCR may be a suitable endpoint to identify a subset of patients who could be successfully treated with more conservative surgery or a non-operative approach. In this setting, prediction of 2yDFS status may be useful to identify subpopulations with the most aggressive tumors. The two-year timeframe was chosen based on initial inspection of the data, and may allow for selection of different chemotherapeutic regimens to reduce DM rates for this subpopulation using an accurate prediction for $2 \mathrm{yDFS}$ status. If these two intermediate endpoints are able to separate the rectal cancer population in several risk groups accurate models predicting these endpoints may allow for better selection of personalized treatments along the treatment scheme (Fig. S1). It is beyond the scope of this paper to deliver accurate prediction models for pCR and 2yDFS, but the focus is on exploration of their role as intermediate endpoints in order to assist future prediction model generation.

\section{Methods}

\section{Study population}

The analyses were performed on data from five large European randomized clinical trials for locally advanced rectal cancer $(N=2795)$ which were pooled on an individual patient level. This included the EORTC trial [8] comparing preoperative radiotherapy with preoperative chemoradiation and observation with postoperative chemotherapy in a $2 \times 2$ factorial design, the French trial [9] comparing preoperative radiotherapy with preoperative chemoradiation, the German trial [10] comparing preoperative chemoradiation with postoperative chemoradiation, the Polish trial [11] comparing preoperative short-course radiation with chemoradiation, and the Italian trial [12] comparing observation with postoperative chemotherapy. The study designs, inclusion criteria, number of patients per trial, and accrual times of the pooled dataset were described in Valentini et al. [13] All patients in the pooled dataset received preoperative radiotherapy (RT) with an average total treatment time of 34-39 days at 1.8 Gy per fraction, followed by surgery 36-47 days after the end of RT. RT dose and the possible addition of preoperative and postoperative chemotherapy (CT) introduced treatment heterogeneity into the database. No patients had metastatic disease at the beginning of treatment. A total of 24 patients who underwent a local excision were excluded in advance.

Although many variables were collected in individual clinical trials, this analysis was restricted to assessing overall survival of four subpopulations: (1) those who achieved a pCR and were disease free after 2 years $(N=246,9.2 \%)$, (2) those with pCR but also a recurrence $(N=21,0.8 \%),(3)$ no pCR but disease free after 2 years
$(N=1868,70.1 \%)$ and $(4)$ no pCR and also a recurrence $(N=528$, 19.8\%). Additional independent variables included RT dose ( $<45 \mathrm{~Gy}, 45 \mathrm{~Gy}$ and $>45 \mathrm{~Gy}$ ), administration of concurrent and/or adjuvant CT (yes/no), the post-RT tumor localization used to determine the surgery strategy (proximal or distal, depending on the tumor's location from the anal verge with $10 \mathrm{~cm}$ cut-off), and the interval between the last fraction of RT and surgery ( $<28$ days, 28-42 days and $>42$ days).

PCR was defined as the absence of tumor cells in the resected specimen (ypTON0). LR was defined as tumor presence in the pelvis or perineum, or in the anastomosis as confirmed by histology. DM was defined as evidence of extrapelvic tumor tissue confirmed by at least two imaging exams. The cumulative incidence of both of these outcomes was reported separately. The absence of both LR and DM within 2 years was defined as disease free. Patients with less than 2 years of follow-up time and without occurrence of an event (death or recurrence) were excluded from the DFS analysis (excluded: $N=301$ ).

\section{Statistical analysis}

Treatment heterogeneity was accounted for by performing subgroup analyses for the patients receiving different $\mathrm{CT}$ regimens in addition to RT: no CT, concomitant or adjuvant CT, or a combination of both CTs. The analyses:

1. The risk ratio at time $t$ was defined as the ratio of cumulative rate of DM at time $t$ divided by the cumulative rate of LR at time $t$. By calculating the risk ratio for each year during the follow-up period, a time trend of the risk ratio was characterized. Confidence intervals were calculated by bootstrapping the ratio of the two rates from the estimated and normal assumed distributions to arrive at the ratio distribution.

2. The long-term outcome between the non-pCR and pCR populations and between non-2yDFS and 2yDFS, as well as five- and ten-year rates for the cumulative incidence of LR, DM, and OS, were reported [14] and confidence intervals were based on the log-log transform [15]. All time intervals were measured from the date of randomization, except for the analyses presented in analysis 4 described below.

3. Logistic regression was used to study the impact of characteristics such as sex, age, tumor localization, cT stage, RT dose, and time to surgery on the odds ratios for the three clinical outcomes of interest: pCR, 2yDFS, and five-year overall survival status (5yOS).

4. Overall survival of the subpopulations defined by their pCR and two-year disease-free status was compared by log rank test, including the four chemotherapy group stratification. The landmark approach [16] was used to avoid the bias of death within 2 years affecting the outcome of investigation (2yDFS).

The analyses were conducted in line with the intention-to-treat principle, and performed using SPSS (version 15.0) and MATLAB (version R2010b, MathWorks Inc.).

\section{Results}

The database characteristics (Table 1) are similar in the four subgroups, with the exception of roughly $4 \%$ more males in the RT-only subgroup, a higher RT dose in the subgroups with concurrent $\mathrm{CT}$ and both CTs, more pT0 in the concurrent CT subgroups compared to the RT-only groups $(16.7 \%$ and $11.2 \%$ vs $5.7 \%$ and $3.6 \%$, respectively), and roughly $8 \%$ more pNO for the concurrent CT subgroup. 
Table 1

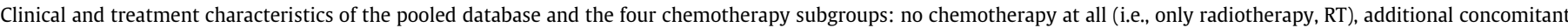

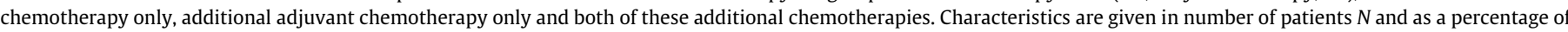
the total number of those patients in the selected group.

\begin{tabular}{|c|c|c|c|c|c|c|c|c|c|c|}
\hline \multirow[t]{2}{*}{ Dataset } & \multicolumn{2}{|l|}{ Pooled } & \multicolumn{2}{|l|}{ RT only } & \multicolumn{2}{|c|}{ RT + conc.chemo } & \multicolumn{2}{|c|}{ RT + adj.chemo } & \multicolumn{2}{|c|}{ RT + both chemo } \\
\hline & $N$ & {$[\%]$} & $N$ & [\%] & $N$ & [\%] & $N$ & {$[\%]$} & $N$ & [\%] \\
\hline Patients & 2795 & {$[100]$} & 366 & {$[100]$} & 839 & {$[100]$} & 501 & {$[100]$} & 1067 & {$[100]$} \\
\hline \multicolumn{11}{|l|}{ Sex } \\
\hline Male & 1952 & {$[69.8]$} & 268 & [73.2] & 584 & [69.6] & 343 & [68.5] & 740 & [69.4] \\
\hline Female & 843 & {$[30.2]$} & 98 & [26.8] & 255 & {$[30.4]$} & 158 & [31.5] & 327 & [30.6] \\
\hline \multicolumn{11}{|l|}{ Age } \\
\hline Median & 62.5 & & 63.0 & & 62.9 & & 62.6 & & 62.0 & \\
\hline Range & $22.0-81.5$ & & $23.0-79.0$ & & $28.4-79.0$ & & $27.0-78.4$ & & $22.0-81.5$ & \\
\hline \multicolumn{11}{|l|}{ cT-stage } \\
\hline $1+2$ & 18 & {$[0.6]$} & - & - & 6 & [0.7] & 1 & {$[0.2]$} & 11 & {$[1.0]$} \\
\hline 3 & 2224 & [79.6] & 309 & [84.4] & 628 & [74.9] & 434 & [86.6] & 841 & [78.8] \\
\hline 4 & 274 & [9.8] & 41 & [11.2] & 90 & [10.7] & 51 & {$[10.2]$} & 92 & {$[8.6]$} \\
\hline No data & 279 & [10.0] & 16 & {$[4.4]$} & 115 & [13.7] & 15 & {$[3.0]$} & 123 & [11.5] \\
\hline \multicolumn{11}{|l|}{ cN-stage } \\
\hline 0 & 311 & [11.1] & 1 & {$[0.3]$} & 230 & {$[27.4]$} & - & - & 80 & [7.5] \\
\hline+ & 551 & [19.7] & 3 & {$[0.8]$} & 154 & [18.3] & - & - & 377 & [35.4] \\
\hline No data & 1933 & [69.2] & 362 & [98.9] & 455 & {$[54.2]$} & 501 & {$[100]$} & 610 & [57.2] \\
\hline \multicolumn{11}{|l|}{ RTdose } \\
\hline$<45$ Gy & 115 & {$[4.1]$} & 18 & [4.9] & 39 & {$[4.6]$} & 18 & {$[3.6]$} & 40 & [3.7] \\
\hline $45-47$ Gy & 2135 & [76.4] & 342 & [93.4] & 645 & [76.9] & 477 & [95.2] & 670 & [62.8] \\
\hline$>47 \mathrm{~Gy}$ & 543 & [19.4] & 6 & [1.6] & 154 & [18.4] & 5 & {$[1.0]$} & 357 & [33.5] \\
\hline No data & 2 & {$[0.1]$} & - & - & 1 & {$[0.1]$} & 1 & {$[0.2]$} & - & - \\
\hline \multicolumn{11}{|l|}{ Conc.CT } \\
\hline No & 867 & [31.0] & 366 & {$[100]$} & - & - & 501 & {$[100]$} & - & - \\
\hline Yes & 1925 & [68.9] & - & - & 839 & {$[100]$} & - & - & 1067 & [100] \\
\hline No data & 3 & {$[0.1]$} & - & - & - & - & - & - & - & - \\
\hline \multicolumn{11}{|l|}{ Localization } \\
\hline Proximal & 1598 & {$[57.2]$} & 184 & [50.3] & 491 & [58.5] & 261 & [52.1] & 645 & [60.4] \\
\hline Distal & 1068 & [38.2] & 150 & [41.0] & 319 & [38.0] & 205 & [40.9] & 389 & [36.5] \\
\hline No data & 129 & {$[4.6]$} & 32 & [8.7] & 29 & [3.5] & 35 & {$[7.0]$} & 33 & [3.1] \\
\hline \multicolumn{11}{|l|}{ pT-stage } \\
\hline 0 & 299 & [10.7] & 21 & [5.7] & 140 & [16.7] & 18 & [3.6] & 120 & [11.2] \\
\hline 1 & 191 & [6.8] & 25 & [6.8] & 64 & [7.6] & 37 & {$[7.4]$} & 64 & {$[6.0]$} \\
\hline 2 & 816 & [29.2] & 99 & [27.0] & 266 & [31.7] & 133 & [26.5] & 312 & [29.2] \\
\hline 3 & 1324 & [47.4] & 185 & [50.5] & 319 & [38.0] & 289 & [57.7] & 520 & [48.7] \\
\hline 4 & 74 & {$[2.6]$} & 15 & [4.1] & 25 & [3.0] & 11 & {$[2.2]$} & 22 & {$[2.1]$} \\
\hline No data & 91 & [3.3] & 21 & [5.7] & 25 & [3.0] & 13 & {$[2.6]$} & 29 & [2.7] \\
\hline \multicolumn{11}{|l|}{ pN-stage } \\
\hline 0 & 1879 & {$[67.2]$} & 233 & [63.7] & 617 & [73.5] & 309 & [61.7] & 707 & [66.3] \\
\hline+ & 827 & [29.6] & 116 & [31.7] & 201 & [24] & 176 & [35.1] & 328 & [30.7] \\
\hline No data & 89 & [3.2] & 17 & [4.6] & 21 & [2.5] & 16 & [3.2] & 32 & [3.0] \\
\hline \multicolumn{11}{|l|}{ Adj.CT } \\
\hline No & 1206 & [43.1] & 366 & [100] & 839 & [100] & - & - & - & - \\
\hline Yes & 1568 & [56.1] & - & - & - & - & 501 & [100] & 1067 & [100] \\
\hline No data & 21 & {$[0.8]$} & - & - & - & - & - & - & - & - \\
\hline
\end{tabular}

\section{Risk ratio}

The overall risk ratio between the rates of DM and LR (Fig. 1A) revealed that, at 1 -year follow-up, six times more patients had developed DM than LR (between 4.2 and 7.5, taking 95\% confidence intervals into account). This number decreases to approximately 2.5 at 2 years and remains relatively constant thereafter, with a slight negative slope. Fig. 1B shows that approximately $80 \%$ of the recurrences occur within the first 4 years, while deaths occur later. For the risk ratios of different CT treatment schemes (neoadjuvant vs adjuvant), similar curves as in Fig. 1 are observed (Fig. 2). These plots show that adding concomitant CT to RT results in a higher DM/LR risk ratio over time compared to no concomitant $\mathrm{CT}$, suggesting that concomitant $\mathrm{CT}$ may result in LR reduction without affecting DM incidence (after 2 years concomitant CT reduces DM by $14.2 \%$ and LR by $49.0 \%$ compared to the non-concomitant CT population). In addition, the population given $\mathrm{CT}$ both adjuvantly and neoadjuvantly show different behaviors on those curves than the other $\mathrm{CT}$ schemes, with the ratio staying relatively constant and decreasing slowly over time. These differences before and after 2 years are confirmed by the results shown in Fig. S2, indicating that aggressiveness of disease is increased for early recurrences, resulting in poor survival, mainly associated with administration of adjuvant CT. For this reason we consider 2yDFS a reliable intermediate endpoint to stratify the population.

\section{Characterization of populations according to $p C R$ and $2 y D F S$ status}

The pCR status was known for 2682 patients; of these, $11.1 \%$ had a pCR $(N=298)$. There were significant differences in longterm outcome between the pCR and non-pCR populations (Table 2). After 10 years, the non-pCR population had a $10.7 \%$ higher LR incidence than the PCR population ( $14.8 \%$ vs $4.1 \%$ ). DM was more frequent in the non-pCR group by $17.1 \%$ after 10 years $(35.2 \%$ vs $18.1 \%$ ). The pCR population had $73.3 \%$ overall survivors vs $57 \%$ in the non-pCR population (16.6\% difference). All differences were 
significant (logrank $p$-values <.001). In the non-2yDFS population $43.1 \%$ had LR and $94.8 \%$ had DM at 5 years, and only $12.9 \%$ survived. These numbers are far more favorable for the $2 \mathrm{yDFS}$ population $(6.1 \%, 16.5 \%$, and $85.3 \%$, respectively).

\section{Multivariate analyses}

When considering the odds ratio's for several predictors (Fig. S3), 2yDFS better resembles OS than pCR as an outcome, which is significant for sex in the pooled population and for tumor localization in the adjuvant CT populations. Longer delays between RT and surgery have an increasing effect on PCR rate but not on survival rate.

\section{pCR vs $2 y D F S$}

Fig. 3 shows that disease-free status at 2 years appears to be a better predictor of OS than $\mathrm{PCR}$. The landmark analysis shows that achieving a PCR is significantly beneficial when there is no recurrence within 2 years of follow-up. In the case of early recurrence, pCR status appears to be statistically irrelevant for OS. The greater effect for OS of achieving 2yDFS than pCR holds for all CT subgroups. Due to the low number of patients in the subgroup $\mathrm{pCR}+$ recurrence within 2 years and the similarity in OS curve development with the no $\mathrm{PCR}+$ recurrence group these are considered as one group in the results. This results in three risk groups: (1) pCR + 2yDFS in 246 patients (9.3\%, with an interval of 2.7$14.9 \%$ depending on treatment group), (2) no PCR $+2 y D F S$ in 1868 patients (70.7\% with interval $64.2-76.6 \%$ ) and (3) no $2 \mathrm{yDFS}$ in 528 patients ( $20 \%$ with interval $17.5-29.3 \%$ ).

\section{Discussion}

This study identified different subpopulations of locally advanced rectal cancer based on their intermediate outcomes in a pooled database of five large European randomized trials. We identified three broad clinical patient subgroups named after their prognosis:

- Excellent ( $10 \%$ with interval 5-15\%): curable patients, highly treatable, organ preservation to be pursued, identified by a pCR and 2yDFS.

- Good ( 70\% with interval 65-75\%): curable patients, require effective local treatment, identified by no pCR- and 2yDFS; for some, the role of combined treatment is questionable.

- Poor ( $20 \%$ with an interval of $17.5-30 \%)$ : ongoing treatment strategies do not lead to cure or patients having an early and late-occurring recurrent disease; They are identified by having no pCR and no DFS within 2 years.

The overall longer-term aim of the identification of these three identified groups is to develop accurate prediction models for the two intermediate outcomes pCR and 2yDFS with data before and along the treatment. Combined predictions of pCR and 2yDFS ( 3 risk groups) using clinical, imaging and biomarkers would allow for personalizing treatment.

Variables related to pathological staging after treatment (pT stage and pN stage) were found to be the main clinical predictors of LR, DM, and OS [13], with patients achieving a pCR having an OS benefit of $14.7 \%$ at 5 years and $16.3 \%$ at 10 years. This is consistent with previous analyses suggesting better outcomes for patients with a pCR $[5,6]$. These studies reported higher five-year survival rates of $91.6 \%$ and $87.6 \%$ respectively for patients who achieve a pCR, compared with $84.3 \%$ in the present study. However, Maas et al. [6] reported a lower survival benefit of $11.2 \%$ at 5 years for patients achieving a pCR. In contrast to our pooled
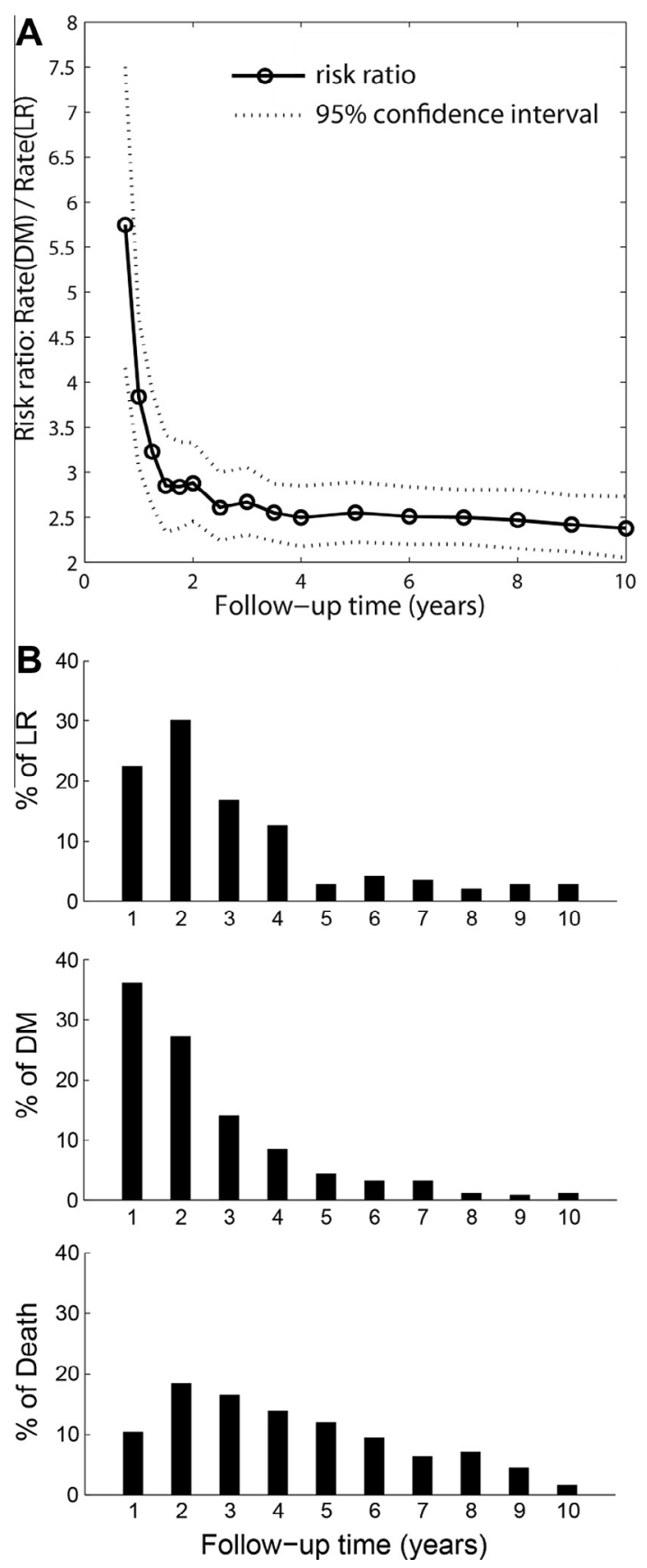

Fig. 1. (A) Risk ratio, cumulative rate of distant metastases/cumulative rate of local recurrences, for all the patients including 95\% confidence interval, and (B) histograms for the percentages of local recurrence and distant metastases occurrences $(100 \%=$ event occurrence at 10 years $)$ for the total population $(N=2795)$ for each year of follow-up.

database, both studies used prospective and retrospective results, and almost all patients received concomitant CT. Therefore, higher absolute rates for the $\mathrm{PCR}$ and non-pCR populations are expected. Also, the studies in Maas et al. were more recent, and the results may reflect improved treatment regimens and pathology assessment. Our study shows the long-term benefits of a PCR for the patients who are recurrence free after 2 years (Fig. 3 ).

In the current study we did not explore formal analyses of surrogacy, as there were too few trials and the treatments were too heterogeneous to perform a valid meta-analysis. Previously, the EORTC 22921 and the FFCD 9203 rectal cancer trials, which are 
No Concomittant chemotherapy
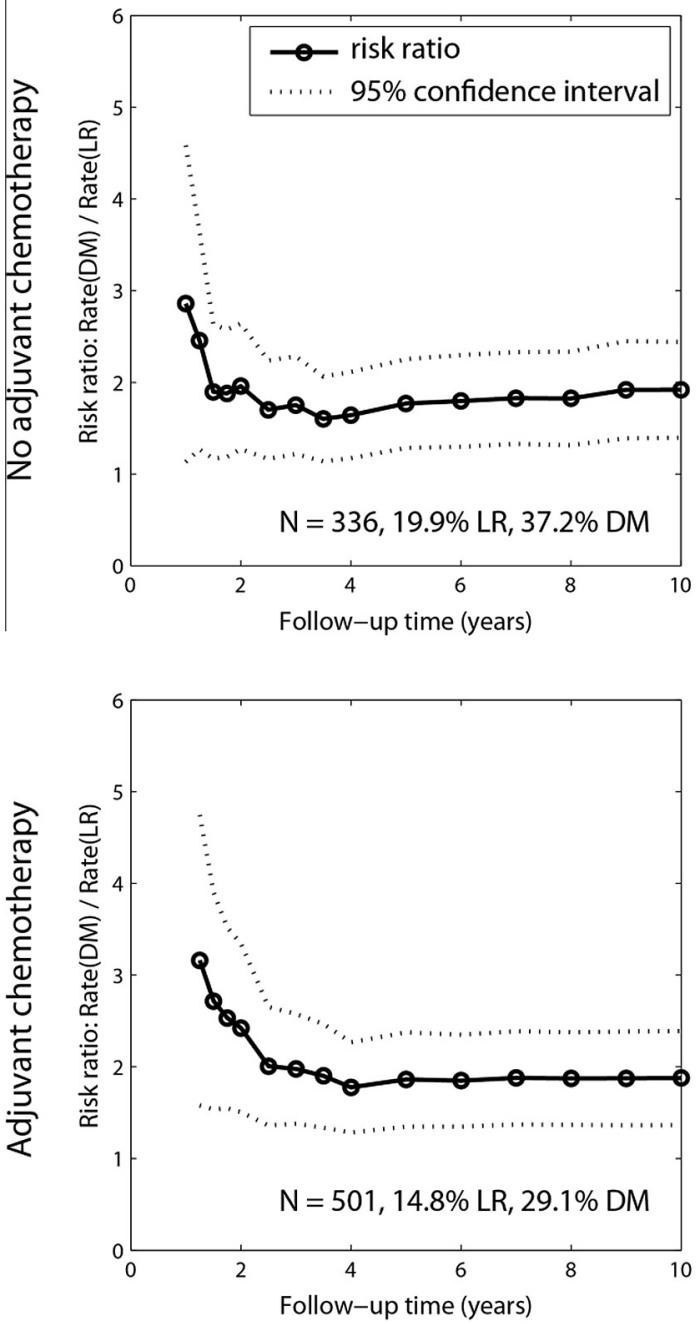

Concomittant chemotherapy
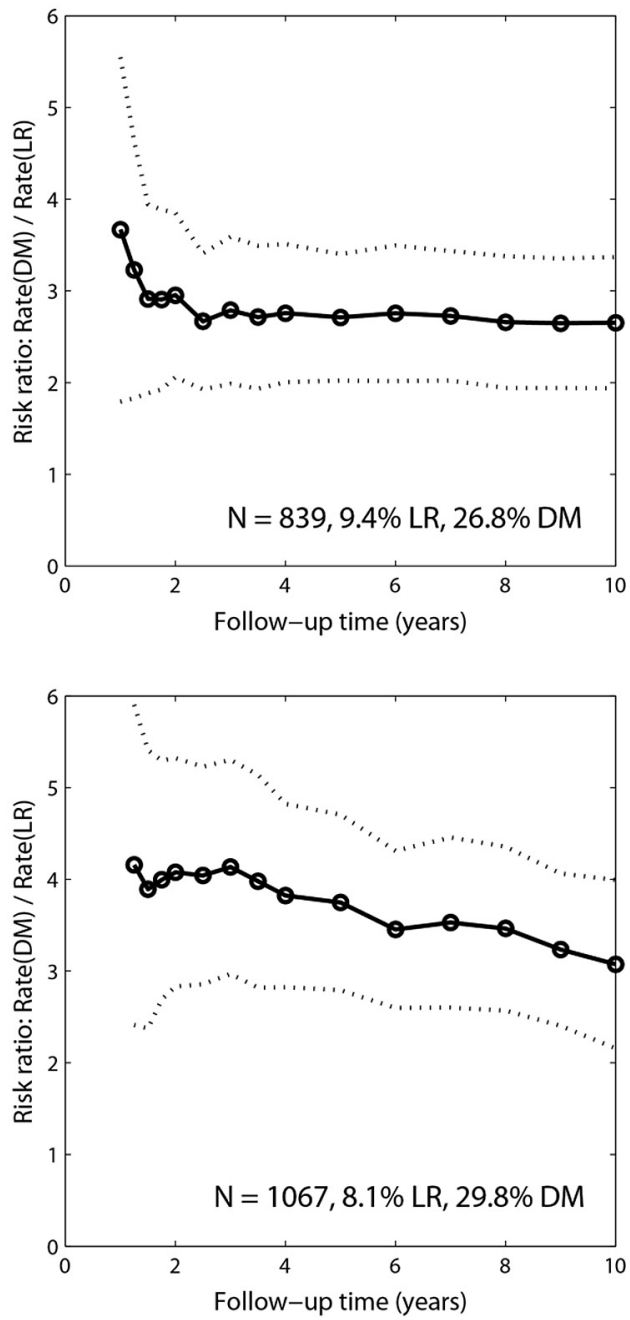

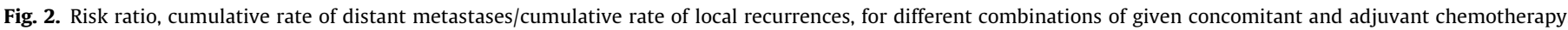
including $95 \%$ confidence intervals over 10 years of follow-up.

Table 2

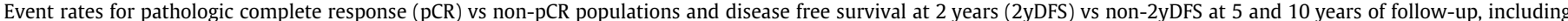
confidence intervals (CI) and $p$-values for the log rank test to test if these two populations are significantly different $(\alpha=.05)$.

\begin{tabular}{|c|c|c|c|c|c|c|c|c|}
\hline \multirow[t]{2}{*}{ Outcome } & \multirow[t]{2}{*}{ Nr. patients } & \multicolumn{2}{|l|}{5 years } & \multicolumn{2}{|l|}{10 years } & \multirow[t]{2}{*}{$p$-Value } & \multirow[t]{2}{*}{ HR } & \multirow[t]{2}{*}{$95 \% \mathrm{CI}[\%]$} \\
\hline & & Rate [\%] & $95 \% \mathrm{CI}[\%]$ & Rate [\%] & $95 \% \mathrm{CI}[\%]$ & & & \\
\hline \multicolumn{9}{|c|}{ Local recurrence rate } \\
\hline Non-pCR & 2415 & 12.8 & [11.5-14.2] & 14.8 & [12.9-16.9] & $<.001$ & 0.32 & {$[0.15-0.68]$} \\
\hline $\mathrm{pCR}$ & 267 & 1.6 & {$[0.6-4.2]$} & 4.1 & [1.9-8.7] & & & \\
\hline Non-2yDFS & 611 & 43.1 & [37.6-49.0] & 46.0 & [39.1-53.5] & $<.001$ & 10.9 & {$[8.5-14.0]$} \\
\hline $2 \mathrm{yDFS}$ & 2184 & 6.1 & {$[5.0-7.4]$} & 8.3 & {$[6.9-10.0]$} & & & \\
\hline \multicolumn{9}{|c|}{ Distant metastasis rate } \\
\hline Non-pCR & 2415 & 32.3 & [30.4-34.3] & 35.2 & {$[33.1-37.4]$} & $<.001$ & 0.59 & [0.42-0.83] \\
\hline $\mathrm{pCR}$ & 267 & 13.0 & [9.3-18.0] & 18.1 & [12.2-26.5] & & & \\
\hline Non-2yDFS & 611 & 94.8 & [90.8-97.5] & 94.8 & [90.8-97.5] & $<.001$ & 21.7 & [18.3-25.6] \\
\hline $2 \mathrm{yDFS}$ & 2184 & 16.5 & [14.8-18.4] & 20.5 & [18.4-22.8] & & & \\
\hline \multicolumn{9}{|c|}{ Overall survival rate } \\
\hline Non-pCR & 2415 & 69.5 & [71.4-67.5] & 57.0 & [59.5-54.4] & $<.001$ & 0.73 & [0.54-0.98] \\
\hline $\mathrm{pCR}$ & 267 & 84.3 & [88.4-78.9] & 73.3 & [80.5-64.0] & & & \\
\hline Non-2yDFS & 611 & 12.9 & [10.0-16.2] & 6.5 & {$[4.1-9.6]$} & $<.001$ & 14.1 & [12.2-16.4] \\
\hline $2 y D F S$ & 2184 & 85.3 & [83.7-86.8] & 71.3 & [68.5-73.9] & & & \\
\hline
\end{tabular}




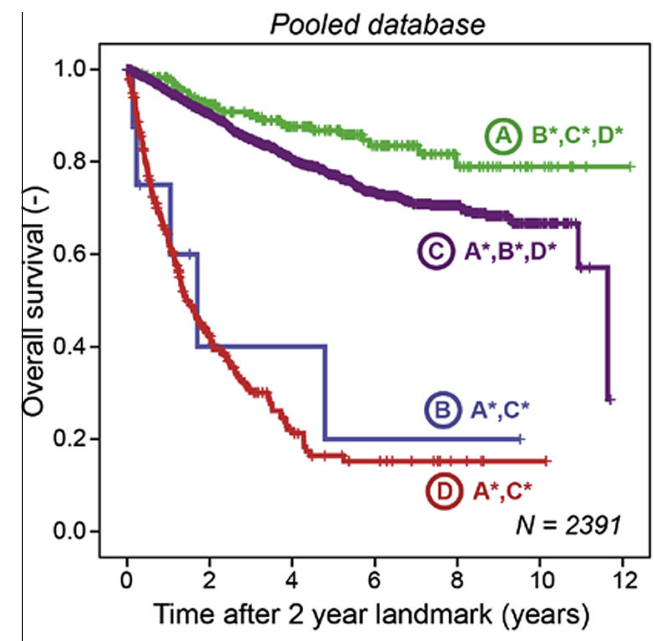

$$
\begin{aligned}
& \text { A }-\longrightarrow \mathrm{pCR}+\text { no recurrence }<2 \text { years } \\
& \text { (B)—— } \mathrm{pCR}+\text { recurrence }<2 \text { years } \\
& \text { (C)—- No } \mathrm{pCR}+\text { no recurrence }<2 \text { years } \\
& \text { (D)— No } \mathrm{pCR}+\text { recurrence }<2 \text { years }
\end{aligned}
$$
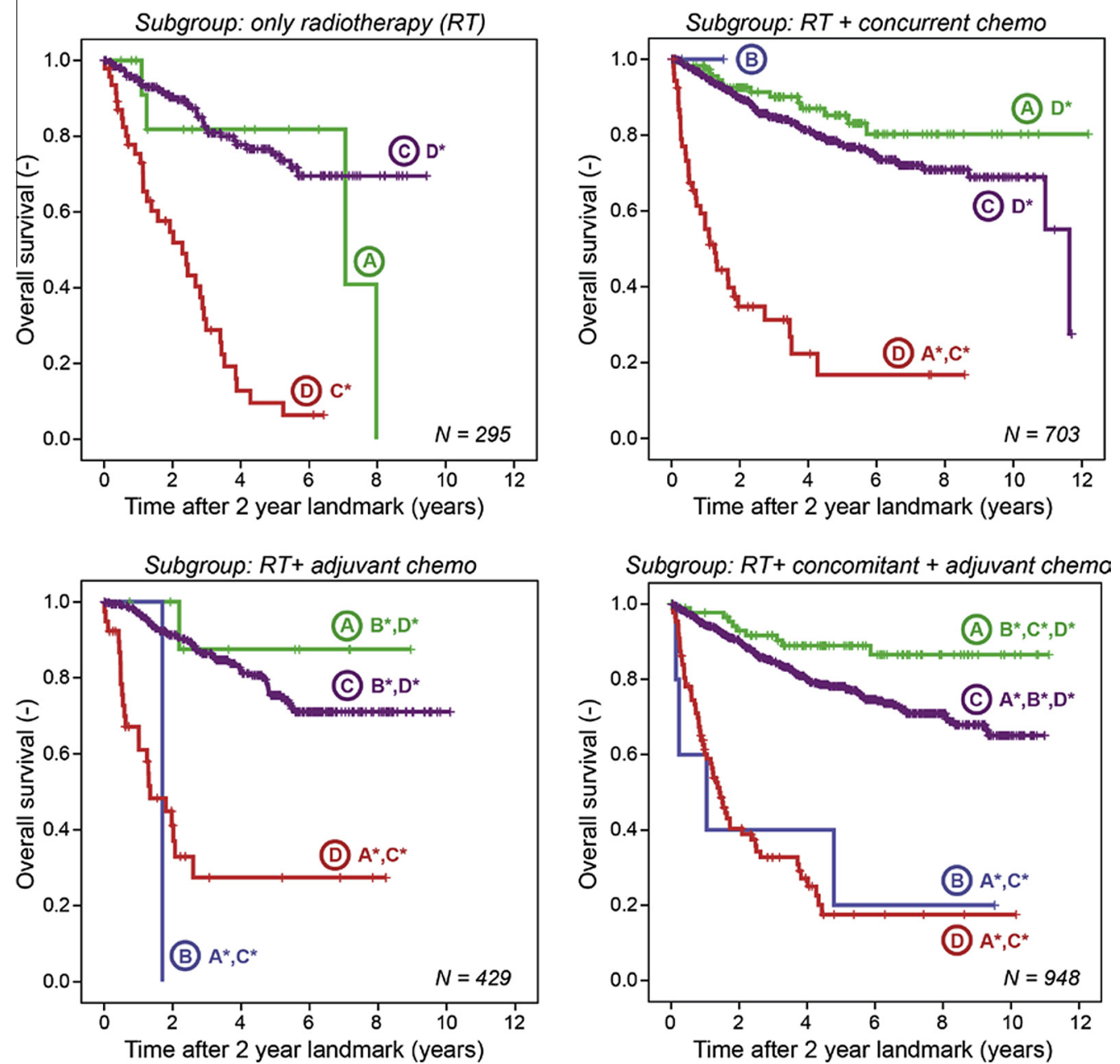

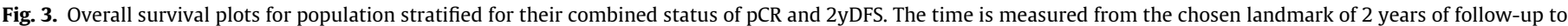

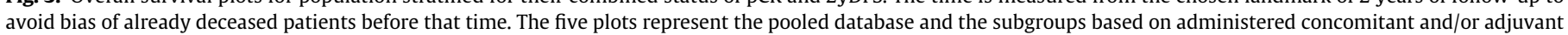

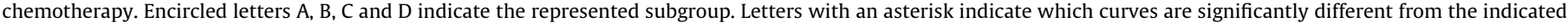
one with $\alpha=.05$.

both included in the current pooled dataset, explored the surrogacy of pCR and progression-free survival (PFS) [17], finding that pCR was not a qualified surrogate endpoint for PFS and OS, while PFS was a surrogate endpoint for OS.

For the pCR subgroup with favorable outcomes, lower RT doses or more conservative surgical strategies might be applied to improve their quality of life. To individualize these treatment decisions, reliable prediction models need to be developed to distinguish between these PCR subgroups.

In the pCR group, $61 \%$ of the LR cases are reported after 5 years post treatment (5y LR: 1.6\%, 10y LR: $4.1 \%$ ). To our knowledge, this has not yet been reported in the literature, though it supports Habr-Gama et al. [18] These findings indicate that patients with pCR require prolonged observation. 
Two-year disease-free status was associated with an OS benefit of $45.5 \%$ and $64.8 \%$ at 5 and 10 years respectively, compared to patients with recurrence within 2 years. This supports the identification of a population of patients with aggressive disease that recurs early and leads to poor survival rates, regardless of treatment [8]. While not being the aim of this study, we identified some prognostic factors, such as sex, cT stage, and tumor localization (Fig. S3), but more imaging and biological markers should be explored to predict 2yDFS reliably. Although not tested for in this paper, pCR status is a plausible prognostic candidate for $2 \mathrm{yDFS}$ based on the studies described above. The comparison between OS according to pCR and 2yDFS showed that the latter had a stronger predictive impact (Table 2, Fig. 3). A similar result was seen for patients who received either chemoradiotherapy alone or who received both chemoradiotherapy and adjuvant CT (Fig. 3).

DFS is superior at predicting survival and should be used as an intermediate endpoint for new prediction models, with the added benefit that the outcome is clear at only 2 years follow-up. Accurate prediction of $2 \mathrm{yDFS}$ is recommended to select patients for adjuvant $\mathrm{CT}$ regimens.

To decide on more or less aggressive treatments and/or more QoL-oriented treatments, it is important to identify the subgroup of patients with early recurrence, because inclusion in prospective randomized trials may negatively affect the findings. Also, the recurrence analysis of the DM/LR ratios (Fig. 1) showed a prevalence of metastases in the first 2 years, indicating a patient group with aggressive disease in whom 5-FU based treatment does not appear to reduce the metastasis rate. The not previously reported finding that the DM/LR ratio remained flat after 2 years, identifies a second group of patients with tumors which can become active after a long follow-up time and have a very slow growth rate. This may be due to an immunological response, and suggests that patients should be followed up for an extended period of time. It appears that for patients receiving concomitant CT the DM/LR ratio is higher than for the patients without, mainly as a result of the overall reduction of LR induced by concomitant CT, resulting in improved local effectiveness without corresponding reduction of DM (Fig. 2). This effect is seen to a lesser extent for DM.

A limitation of the study is that it is based on older trials, meaning that the quality of imaging, surgery and pathology was not equal to current standards. Although we believe that the large number of patients in the pooled dataset provides us sufficient confidence to support our conclusions, these findings should be confirmed in newer trials. It should also be emphasized that, in three trials $(N=1244)$, adjuvant CT was not randomized or mandated; $73 \%$ did receive adjuvant $\mathrm{CT}$, and the percentage of these patients with $\mathrm{pN}+$ stage was significantly higher than in the group without adjuvant CT, although other factors like age, CRM status and co-morbidity may be involved as well in the choice for adjuvant chemotherapy. The higher $\mathrm{pN}+$ frequency may introduce a possible bias, but it is likely to be small given the patient numbers involved ( $14 \%$ of the total population had $\mathrm{pN}+$ combined with adjuvant $\mathrm{CT})$.

\section{Conclusion}

This study identified different populations of rectal cancer patients: highly responsive patients ( $\mathrm{PCR}$ and disease free after 2 years), good responsive curable patients (no PCR but disease free thereafter), and patients with early and late recurrence regardless of pCR status (poor prognosis). While both intermediate outcomes are prognostic (confirming our hypotheses), 2yDFS is stronger than pCR for OS. pCR predictions may identify a minority of highly responsive patients for whom surgery can be tailored, organ preservation promoted, and quality of life or other patient-reported outcomes improved, whereas 2yDFS predictions identify less responsive patients who may benefit from more aggressive CT. Therefore, 2yDFS should also be considered as an intermediate endpoint in future trials, focusing on identifying and evaluating early predictors for $\mathrm{pCR}$ and 2yDFS in order to adapt treatment most efficiently.

\section{Conflict of interest statement}

None of the authors of paper RO-D-13-00796R1 have conflicts of interests to publish this paper.

\section{Appendix A. Supplementary data}

Supplementary data associated with this article can be found, in the online version, at http://dx.doi.org/10.1016/j.radonc.2015.02. 001.

\section{References}

[1] Sullivan R, Peppercorn J, Sikora K, Zalcberg J, Meropol NJ, Amir E, et al. Delivering affordable cancer care in high-income countries. Lancet Oncol 2011;12:933-80.

[2] Sargent D, Shi Q, Yothers G, Van Cutsem E, Cassidy J, Saltz L, et al. Two or three year disease-free survival (DFS) as a primary end-point in stage III adjuvant colon cancer trials with fluoropyrimidines with or without oxaliplatin or irinotecan: data from 12,676 patients from MOSAIC, X-ACT, PETACC-3, C-06, C07 and C89803. Eur J Cancer 2011;47:990-6.

[3] Lambrecht M, Deroose C, Roels S, Vandecaveye V, Penninckx F, Sagaert X, et al. The use of FDG-PET/CT and diffusion-weighted magnetic resonance imaging for response prediction before, during and after preoperative chemoradiotherapy for rectal cancer. Acta Oncol 2010;49:956-63.

[4] Wang Y, Cummings B, Catton P, Dawson L, Kim J, Ringash J, et al. Primary radical external beam radiotherapy of rectal adenocarcinoma: long term outcome of 271 patients. Radiother Oncol 2005;77:126-32.

[5] Capirci C, Valentini V, Cionini L, De Paoli A, Rodel C, Glynne-Jones R, et al Prognostic value of pathologic complete response after neoadjuvant therapy in locally advanced rectal cancer: long-term analysis of 566 ypCR patients. Int J Radiat Oncol Biol Phys 2008;72:99-107.

[6] Maas M, Nelemans PJ, Valentini V, Das P, Rodel C, Kuo LJ, et al. Long-term outcome in patients with a pathological complete response after chemoradiation for rectal cancer: a pooled analysis of individual patient data. Lancet Oncol 2010;11:835-44.

[7] Gelman R, Gelber R, Henderson IC, Coleman CN, Harris JR. Improved methodology for analyzing local and distant recurrence. J Clin Oncol 1990;8:548-55.

[8] Bosset JF, Collette L, Calais G, Mineur L, Maingon P, Radosevic-Jelic L, et al. Chemotherapy with preoperative radiotherapy in rectal cancer. $\mathrm{N}$ Engl J Med 2006;355:1114-23.

[9] Gerard JP, Conroy T, Bonnetain F, Bouche O, Chapet O, Closon-Dejardin MT, et al. Preoperative radiotherapy with or without concurrent fluorouracil and leucovorin in T3-4 rectal cancers: results of FFCD 9203. J Clin Oncol 2006;24:4620-5.

[10] Sauer R, Becker H, Hohenberger W, Rodel C, Wittekind C, Fietkau R, et al Preoperative versus postoperative chemoradiotherapy for rectal cancer. $\mathrm{N}$ Engl J Med 2004;351:1731-40.

[11] Bujko K, Nowacki MP, Nasierowska-Guttmejer A, Michalski W, Bebenek M, Kryj M. Long-term results of a randomized trial comparing preoperative shortcourse radiotherapy with preoperative conventionally fractionated chemoradiation for rectal cancer. Br J Surg 2006;93:1215-23.

[12] Sainato A, Cernusco Luna Nunzia V, Valentini V, De Paoli A, Maurizi ER, et al. No benefit of adjuvant Fluorouracil Leucovorin chemotherapy after neoadjuvant chemoradiotherapy in locally advanced cancer of the rectum (LARC): long term results of a randomized trial (I-CNR-RT). Radiother Oncol 2014 Nov; $113: 223-9$

[13] Valentini V, van Stiphout RG, Lammering G, Gambacorta MA, Barba MC, Bebenek $\mathrm{M}$, et al. Nomograms for predicting local recurrence, distant metastases, and overall survival for patients with locally advanced rectal cancer on the basis of European randomized clinical trials. J Clin Oncol 2011;29:3163-72.

[14] Kaplan EL, Meier P. Nonparametric estimation from incomplete observations. Am Stat Assoc 1958;53:457-81.

[15] Kalbfleisch JD, Prentice RL. The statistical analysis of failure time data. 2nd ed. Hoboken (NJ) USA: John Wiley \& Sons; 2002.

[16] Anderson JR, Cain KC, Gelber RD. Analysis of survival by tumor response. J Clin Oncol 1983;1:710-9. 
[17] Bonnetain F, Bosset JF, Gerard JP, Calais G, Conroy T, Mineur L, et al. What is the clinical benefit of preoperative chemoradiotherapy with 5FU/leucovorin for T3-4 rectal cancer in a pooled analysis of EORTC 22921 and FFCD 9203 trials: surrogacy in question? Eur J Cancer 2012;48:1781-90.
[18] Habr-Gama A, Perez RO, Proscurshim I, Campos FG, Nadalin W, Kiss D, et al. Patterns of failure and survival for nonoperative treatment of stage c0 distal rectal cancer following neoadjuvant chemoradiation therapy. J Gastrointest Surg 2006;10(10):1319-28 [discussion 28-9]. 